\title{
A proposal for pharmacovigilance data restructuring at the teaching hospital
}

\begin{abstract}
Introduction: The increasing volume of pharmacovigilance data froom reports of Adverse Drug Reaction (ADR) indicates the need for a database (DB) to manage its electronic records. Objective: Thus, the objective of the present study is to prepare a prototype computing environment that will permit data recording, storage and recovery aimed at generating information and creating an effective database within the Pharmacovigilance Unit of the Professor Edgard Santos Teaching Hospital in Salvador, Bahia, Brazil. Methods: This descriptive study managed by pharmacists and development systems professionals whose object of study was based on preexisting electronic spread sheets used to store data on adverse drug reactions since 2000. The work consisted of three principal steps: the normalization of the data, relationships between the data collected, and database modeling with implementation of the information system. Results: This restructuring allows a database to be consolidated quickly and consistently, with reliable data duly completed and analyzed. Conclusion: Thus, the HUPES Pharmacovigilance Information System (SIFAVI) was modeled, which integrates into a web application na easy mechanism for storing and recovering the data stored in the database. This also permits the data on adverse drug reactions to be categorized and crosschecked, enabling more precise inferences to be made, thus rendering this practice simpler for users and improving the culture of notifying and validating adverse drug reactions.
\end{abstract}

Keywords: Database, Pharmacovigilance, Drug-Related Side Effects and Adverse Reactions.

\section{Uma proposta de reestruturação dos dados da farmacovigilância de um hospital universitário}

Universidade Federal da Bahia

Submitted: 03/12/18

Resubmitted: 09/04/19

Accepted: 11/06/19

\section{Resumo}

Introdução: $O$ crescente volume de dados da farmacovigilância provenientes de notificações de Reações Adversas a Medicamentos (RAM) indica a necessidade de um banco de dados (BD) para gerir seus registros eletrônicos. Objetivos: Desse modo, o objetivo deste trabalho foi à criação de um ambiente computacional que permitisse o registro, armazenamento e recuperação de dados de RAM do Centro de Farmacovigilância do Hospital Universitário Professor Edgard Santos, Salvador-BA. Métodos: Este estudo descritivo foi dirigido por farmacêuticos e profissionais da área de desenvolvimento de sistemas cujo objeto de estudo foi proveniente de planilhas eletrônicas preexistentes que armazenavam as RAM desde o ano 2000. O trabalho consistiu em três etapas principais: normalização dos dados, relação entre dados da coleção e modelagem da base de dados com implementação do sistema de informação. Resultado: Através dessa reestruturação, foi possível consolidar um $\mathrm{BD}$ de forma rápida e consistente, com informações seguras, devidamente preenchidas e analisadas. Conclusão: Assim foi modelado o Sistema de Informação da Farmacovigilância do HUPES (SIFAVI) que integra, em uma aplicação web, um mecanismo facilitado de armazenamento e recuperação dos dados armazenados no BD. Além de ser factível categorizar e cruzar os dados das RAMs, de modo a fazer inferências mais precisas, viabilizando esta prática pelos usuários e ampliando a promoção da cultura da notificação e validação das reações.

Palavras-chave: base de dados, farmacovigilância, Efeitos Colaterais e Reações Adversas Relacionados a Medicamentos.
DOI: 10.30968/rbfhss.2019.102.0409

ISSN online: $2316-7750$

Corresponding Author:

Sayuri Rocha Yamashita sryamashita@gmail.com 


\section{Introduction}

Pharmacovigilance is a science and a set of activities related to the identification, assessment, understanding and prevention of adverse effects or any other problem related to drug use. Its objectives include improving public health, patient care, drug safety, evaluating and monitoring treatment benefits, encouraging rational drug use, promoting health education, and effective communication to the public. ${ }^{1}$

In terms of electronic records at national level, the National System of Notification for Sanitary Surveillance (Notificações para a Vigilância Sanitária, Notivisa) stands out, created through the Ministerial Ordinance No. 1.660 of July $22^{\text {nd }}, 2009$ of the Ministry of Health. ${ }^{2}$ This is a computerized system that receives reports of adverse events and technical complaints related to products under health surveillance, such as medications, vaccines, clinical research studies, blood (or components), among others. After the creation of this service, there was an increase in notifications due to its stimulus, ease of access and the compilation of data to be studied about a certain drug. ${ }^{2}$

Records are commonly made on paper, a practice that has generated large amounts of waste, increased risk of loss and duplication of information, and inappropriate use to guide treatments. ${ }^{3}$ On the other hand, electronic health records enable the broad spectrum of clinical investigation, including adverse drug reactions (ADRs), which reduces the time to detect cases.

Given this context, it is impossible to think of a hospital and its services without the performance of medical informatics, which has stood out as a great ally of health professionals. Thus, considering the increasing availability and offer of the service, several data collection techniques were specifically developed for the early detection of drug safety signs. ${ }^{4}$ Meanwhile, pharmacovigilance services have reduced the number of databases (DBs) set up to manage the collection at the hospital level. DBs are important tools for recording and storing structured data. ${ }^{5,6}$ The data, in turn, are representations of facts suitable for communication, interpretation or processing, by individuals or by automated means. The application is the physical structure of storage and access to such data, in direct interaction with a DB. ${ }^{6}$

Health DBs have made great strides and contributed to studies and projects as a special source of data, which can be routinely collected to provide input to a range of research questions. The applications are advantageous because they enable the study of rare events in the face of the large storage capacity, are low cost and fast, which makes the DBs accessible and efficient. In addition, they present the clinical routine in real time, given the practicality of entering and retrieving information.
The increasing supply of data from the reporting process, as well as a shortage in hospital-level technology management, is a typical scenario for the adoption of $\mathrm{DBs}$ that structure data and provide a mechanism that facilitates information retrieval in a short space of time. ${ }^{8}$ Given this scenario, the present descriptive study aimed to prepare a computational environment that would favor data recording and retrieval, promoting the generation of information and the restructuring of a database of the pharmacovigilance service of Professor Edgard Santos University Hospital (Hospital Universitário Professor Edgard Santos, HUPES).

Through this restructuring it will be possible to consolidate a database quickly and consistently, with secure information, duly completed and analyzed. In addition to categorizing and cross-referencing ADR data to make more accurate inferences, it will facilitate this practice by users and broaden the promotion of a culture of notification and validation of reactions. In addition, it will serve as an instrument for research and documentation in epidemiological and socioeconomic terms about the safety profile of the treatments, acting in the development of public health policies and as a source for research and studies, considering the university-hospital environment.

\section{Methods}

This descriptive study on the elaboration of the pharmacovigilance database took place between February 2017 and February 2018, at the HUPES Pharmacovigilance Center and at the Department of Computer Science of the Federal University of Bahia. The team is comprised of pharmacists and IT professionals who worked together on modeling, implementing and applying the database. The material used for this work consisted of spreadsheets developed in the Microsoft Excel program, which described all the ADRs registered from 2000 to the present time. Figure 1 presents a cutout of the spreadsheet used to store such records. From the beginning, all pharmacovigilance records are stored physically in notification reports and digitally in a directory, with restricted access to those responsible for this sector, backed up monthly. At the end of each month, these professionals produce reports and graphs from the data entered in these spreadsheets and send them to regulatory agencies.

The increased volume of notifications has made the task of managing stored data difficult, resulting in increased time to retrieve this information. In order to deal with this growing volume of data, the construction of an information system that contemplated the registration and facilitated access to this database was idealized.

Figure 1. Spreadsheet used to store ADR records.

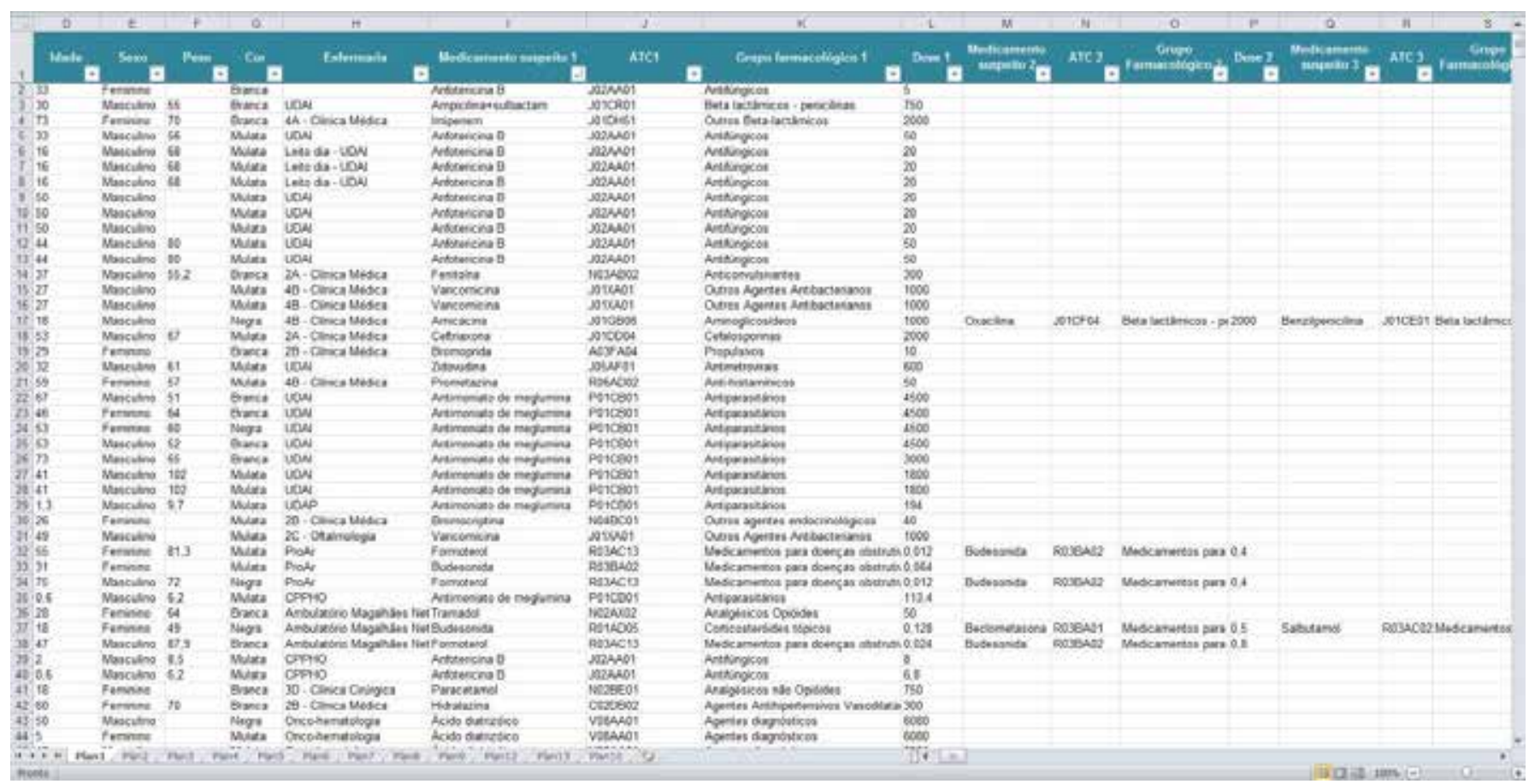


These impressions are the result of several discussions with the team of pharmacists working in the pharmacovigilance sector and aimed to raise the challenges and difficulties by identifying the main limitations of the service. In addition, the ADR storage environment was presented, considering the need to measure the real importance of its application. Brainstorming involved aspects of computerized space, the time of data entering and collection, and the reliability and confidentiality of the information. In addition, it opened a discussion space for those responsible for this service to point out other aspects that would not be recognized with direct questions.

After analyzing these reports, the software system (sequence of instructions to be interpreted) was created to support pharmacovigilance activities. This activity consisted of three stages, as detailed below:

Stage 1: Data normalization - This stage was performed in order to analyze the stored data and to restructure them, to avoid redundant fields. The initial data collection gathered nearly 250 attributes in a spreadsheet. The attributes include all the data required for the ADR validation process. As an activity of this stage, the role of each of these attributes was analyzed. At this time, it was observed that not all of them were related to the ADR, which hindered the interpretation. With the restructuring, there was the need to insert new fields necessary for the validation process, e.g., data such as the date of receipt and end of validation, expert assessment of that reaction, occurrence by self-medication, if the ADR was the cause for hospitalization, if it was a predictable event and if the reaction was dropped.

Stage 2: Relationship between collection data - This stage consisted of building the relationships between the data in order to structure the creation of the DB (c.f. Fig. 2). Data from the spreadsheet were regrouped and the terms that made up the related vocabulary were standardized, such as the categorized terms of the ADRs, which were distinctly entered from the beginning. Some classifications were populated with their synonyms, varying by users. This would lead to a misinterpretation in the final analysis of these data. To avoid such duplicity, eventually variable terms were standardized, such as the pharmacological grouping; or previously considered standard terms, such as the International Code of Diseases(ICD10) and the Anatomical Therapeutic Chemical (ATC) code.

Figure 2. Entity-Relationship Diagram of the SIFAVI's Database

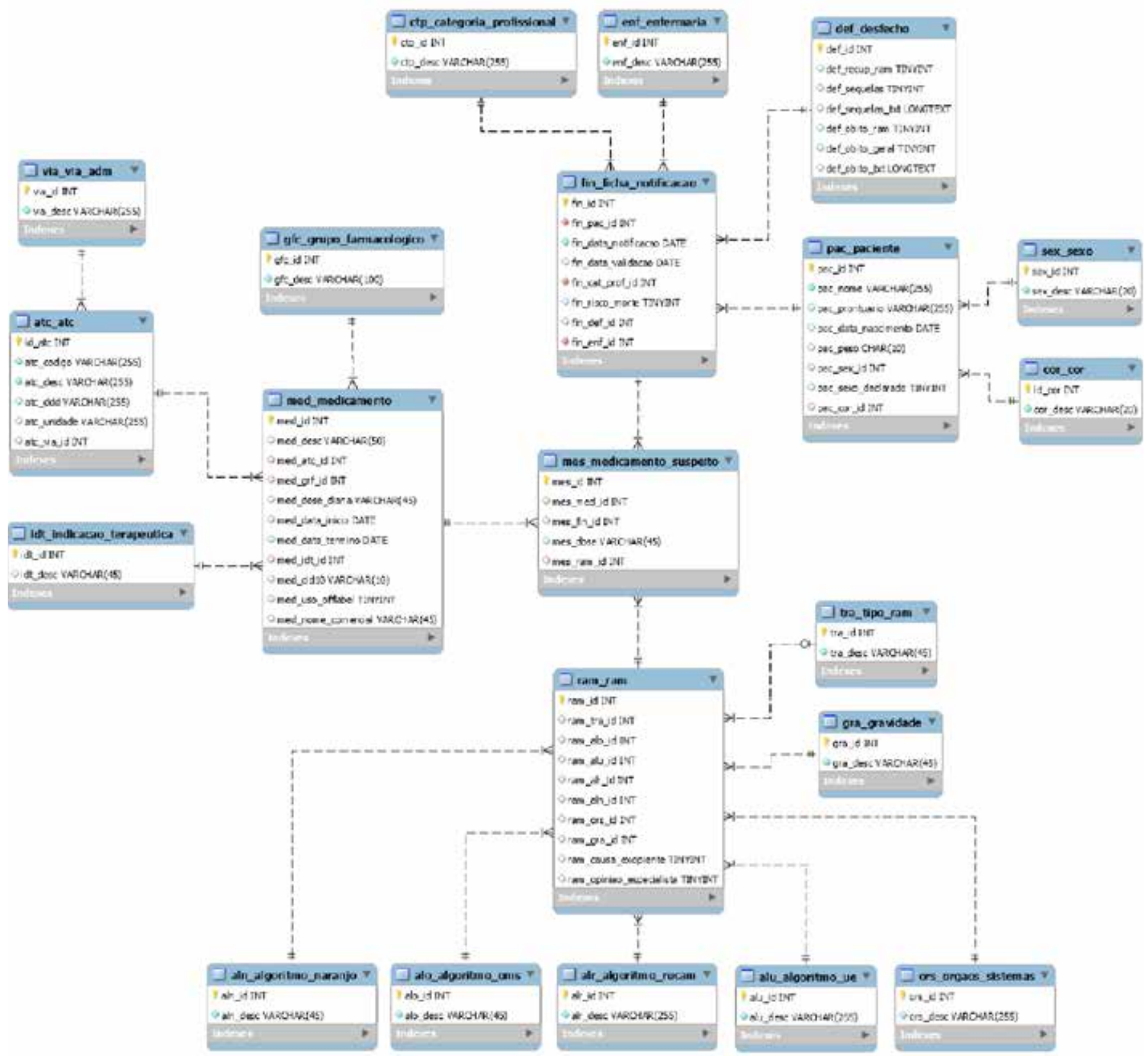


Stage 3: Database modeling and implementation of the information system - The last stage consisted in the specification and modeling of SIFAVI: HUPES Pharmacovigilance Computerized System. At this stage the main parts and objects involved, their possible actions and responsibilities, their characteristics and how they interact with each other were identified. The main artifacts produced in this stage were the definition of the Entity-Relationship Model (ERM) and the functional prototype of SIFAVI. The first is a conceptual model used in Software Engineering to describe the objects (entities) involved in a business domain, with their characteristics (attributes) and how they relate to each other (relationships). In general, this model abstractly represents the structure that the database of the application will have. Figure 2 presents the SIFAVI's ERM, which brings together all entities (represented by tables in the model), attributes (the list of elements described in each table), and the main relationships between them.

\section{Results}

The following is a prototype that in turn integrates into a web application an easy mechanism for storing and retrieving data stored in the DB.
Figure 3 presents SIFAVI's splash screen. The screen header includes a list with hyperlinks to the registration pages of all entities presented in the ERM. In addition, the screen includes a dashboard contemplating the four main entities of the application: (i) Paciente (Patient), (ii) Ficha de notificação (Notification Form), (iii) RAM (ADR) and (iv) Medicamento Suspeito (Suspected Medication). Each such session takes you to a registration page where you can access records stored in the DB, as well as insert new records, edit or delete existing ones.

Figure 4 presents the capture of the Ficha de Notificação registration screen. Here you can see the fields that must be completed. Figure 5 also illustrates how the relationship between entities occurs in practice. The options presented for completing the field Paciente are the data from Table pac_paciente of the DB, the entity that represents the patients registered in the system. The relationship between "Paciente" and "Ficha de Notificação" is displayed on Figure 5, which provides a simplified view of Figure 2, emphasizing only the relationship between the two entities described above. The other relationships presented in the ERM are implemented similarly in the system by automatically filling in the fields.

Figure 3. Home Screen Capture of the HUPES Pharmacovigilance Information System - SIFAVI.

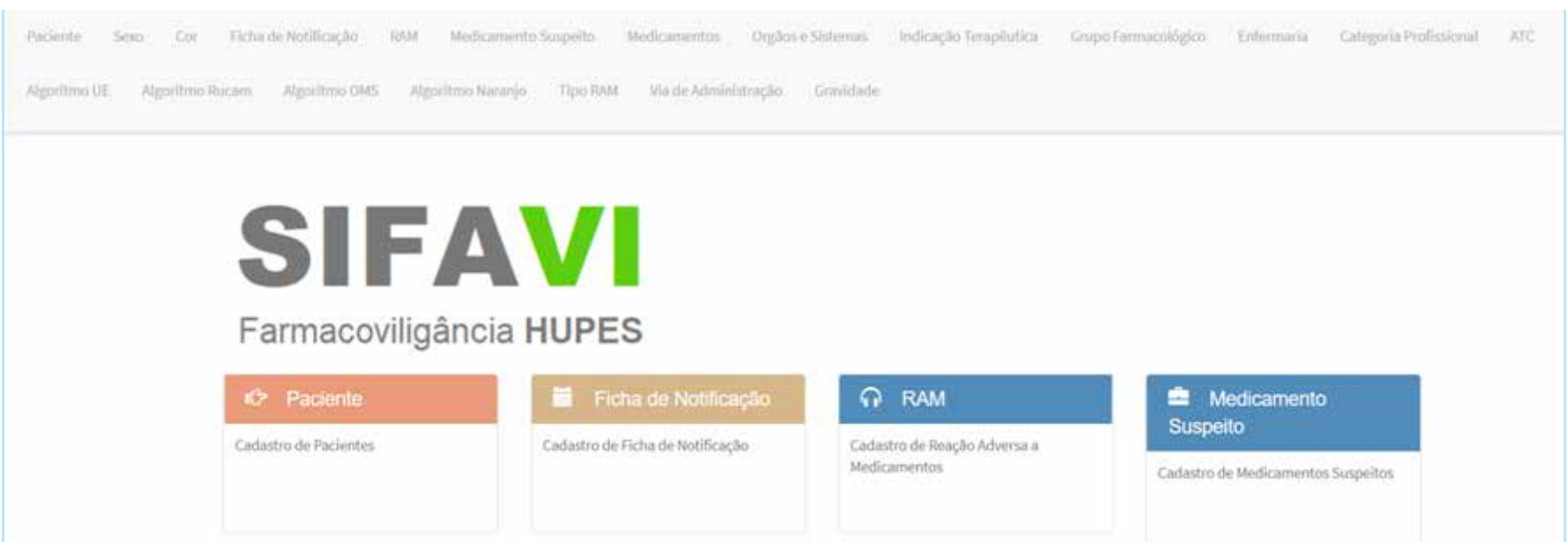

Figure 4. "Ficha de Notificação" page screen.

\section{Nova Ficha de Notificação}

Paciente
Data da Notificaçăo*

Data da Validaçào

Categoria Profissional do Notificador *

Há Risco de Morte? *

Enfermaria *

\begin{tabular}{|l|}
\hline Favor Selecionar \\
\hline Favor Selecionar: \\
\hline Maria do Rosário Penteado \\
\hline \\
\hline
\end{tabular}

$\operatorname{Sim} \square$ Não

Favor Selecionar 
In addition to enabling the registration of records for each entity, the prototype implements listing and search functionality for records. Figure 6 presents the screen of the ward records screen, which lists the items registered in Table enf enfermaria of the ERM. It has the attributes enf_id- which brings the unique identifier of the record, and enf desc - which brings the description of the ward. The upper part of the figure presents a search field, which serves to search any data stored in the Table. The scenario illustrated in Figure 6 brings the user simulating the search for the term "pediatria" ("pediatrics"). Quickly, the system returns the text "1a - Pediatria / Udap" ("1a - Pediatrics / Udap", retrieved from the data recorded in Table enf_enfermaria. The same applies to any other screen of the application, which greatly facilitates the search for data stored in the DB tables.

The relationships between the entities are also presented on the screens that list the records. In the scenario presented in Figure 6, the index (ID) record $2-1 a-$ Pediatria / Udap has a relationship with another entity. Clicking on the corresponding icon and expanding the table gives access to the relationship data. The expanded table shows the patient records that are associated with a given ward. This is possible because there is a relationship between the entities Enfermaria, Ficha de notificação and Paciente, according to Figure 5. The hyperlinks, arranged throughout the application, greatly facilitate navigation between distinct entities, which are related to each other.

It is noteworthy that SIFAVI is still in the prototype phase, although it already has several patient record keeping functionalities and notification forms. In a next phase, which will consist of the approval of the application, it will be necessary to populate the $\mathrm{DB}$ with real data. This will enable automated report generation, considering various aspects of interest of HUPES Pharmacovigilance, without having to manipulate data in a spreadsheet.

Figure 5. A simplified view of the ERM, showing the relationship between the entities "Paciente", "Ficha de Notificação" and "Enfermaria" ("Ward").

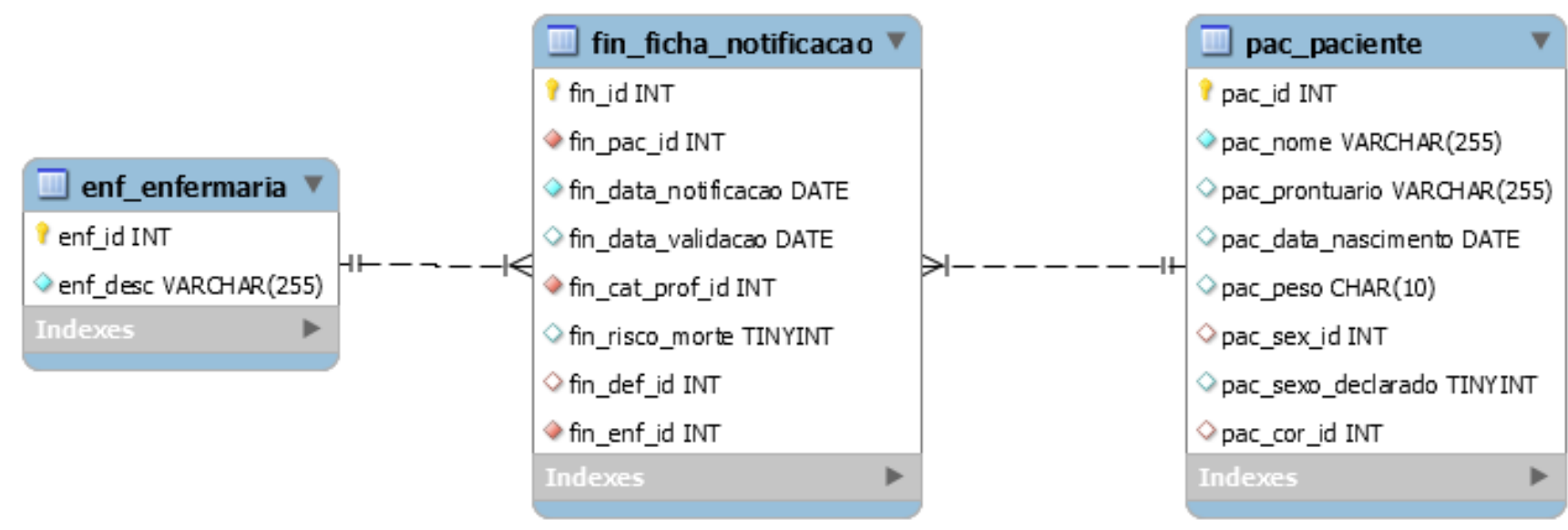

Figura 6. Captura de Tela do cadastro de enfermaria, apresentando dados relacionados

A . Enfermaria-

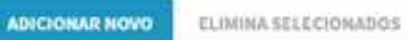

Displaying 1-5 of 520 - E.

\begin{tabular}{|c|c|c|c|}
\hline & a & 10 & Enfermaria \\
\hline 10 & 日 & 1 & 0 -Uti2/Uco \\
\hline 10 & 日 E1 & 2 & 1a - Pediatria / Udap \\
\hline
\end{tabular}

\begin{tabular}{|l|l|l|l}
\hline ADICIOLAR & ELIMINAR \\
\hline
\end{tabular}

\begin{tabular}{|c|c|c|c|c|c|c|c|c|c|}
\hline & a & Finld & Paciente & Data da Notificaç̄on & Data da Validaçie & Categoria Profissional do Notificador & Há Risco de Morte? & Fin Defid & Enfermaria \\
\hline$\therefore a$ & 曰E & 0 & $\begin{array}{l}\text { Maria do } \\
\text { Rosśrio } \\
\text { Pertedodo }\end{array}$ & $06 / 02 / 2018$ & & Enfermeiro & & & $\begin{array}{l}\text { Pa- } \\
\text { Pediatria / } \\
\text { Udap }\end{array}$ \\
\hline
\end{tabular}

\begin{tabular}{|c|c|c|}
\hline$P Q: B E$ & 3 & 1b-Oncohernatologia \\
\hline$\angle Q B B$ & 4 & 1d-Cardiologia \\
\hline
\end{tabular}




\section{Discussion}

The main challenge encountered in this project was to provide a consistent DB capable of storing approximately 1,500 reactions recorded so far, while organizing the terms used in the past that would make it impossible to generate information for a future study.

According to the research discussion prior to the creation of the database, all pharmacists involved reported that there was no adequate and safe computerized storage environment for the ADRs. All stated that there is a delay in the time of insertion and consultation of data in the spreadsheet, considering its format and the number of attributes. The same report was identified when asked if the procedure for filling in data and creating reports from them was easily feasible. The main answers were summarized in the difficulty of visualization due to the length of the spreadsheet, lack of uniformity and standardization of terms and the absence of important electronic information, forcing the professional to return to manual files. In addition, only at the end of the validation process was data entered into the spreadsheet, accumulating tokens in a physical space. To resolve this limitation, suspicions of ADRs that were discarded for not having the drug as the cause of the reaction were not recorded in the system, when they should be accounted for.

According to Rector, ${ }^{10}$ to manage the excess information and store it properly, it must be registered in a database. Thus, uniformity of data and use of a common language is required to share information between the health care network and its professionals. ${ }^{11}$ Thus, a database capable of producing and connecting HUPES ADR notification information was structured.

The spreadsheet was restructured as a functional prototype that first needed essential modifications, such as the standardization of the terms used and the normalization of data. In this new configuration, it is not allowed to insert two records with the same keyword or to delete something related to another attribute, so that there is no data inconsistency. Some new attributes were inserted when identifying the importance of complementing the validation with this information.

As quoted by the Regional Committee on Health Data Networks $s^{5}$ of the Washington Medicine Institute, data comprehensiveness and inclusion should be considered as two critical dimensions of a DB. This relevant completeness refers to the amount of information required, such as demographic and administrative data, health status, and outcome, while inclusion mentions the DB coverage group. The more comprehensive and inclusive, the more it will reflect the current situation accurately, responsibly and up to date. Thus, it is important to notify and validate all suspicions of ADRs in the population.

According to Hennessy et al., these hospital medical data are widely used in epidemiological research and sometimes may be incomplete, which is recognized as a potential problem, but its magnitude not yet described. One of the factors that this author brings about is the error in data transfer that may result in loss and become undetectable later. Data validity is crucial for defining outcomes in studies. In addition, researchers who use DBs as references for their research need this information reliability. In addition, health data impurities are costly to the system, obscure research, and directly affect the quality of patient care, according to Peabody et al. ${ }^{13}$ In this study, which investigated medical records, patient files and computerized administrative databases, it was found that $8 \%$ of the forms were lost and that $22 \%$ were incorrectly entered in the database. Only $57 \%$ of the data were correct, demonstrating the big significance of errors in computerized health systems. In the past scenario of the pharmacovigilance area of the HUPES, due to the way the spreadsheet was worked on, there was a high risk of data loss or deviation, either in supply or transfer, as stated by the professionals.

Regarding data provision errors, the accuracy of the information entered through the creation of previously established fields is guaranteed to avoid variability in terms for identifying ADRs and typing errors. In addition, easy access to the system will enable reporting management capabilities that faithfully represent the validations and meet regulatory and community requirements.

When it comes to pharmacovigilance, information exchange and data provision on ADRs are of utmost importance for worldwide health surveillance data generation and estimates. Through the databases, a series of ADR notifications of patients from a given hospital - at the micro level - and from countries - at the macro level - are grouped, speeding up and strengthening its detection. The product of these databases has led to major advances, especially in the safety of medications and their users. Several registrations have generated important changes such as leaflet modifications, creation of informational warnings about the drug and its risks, and regulatory agency interventions, such as many of the HUPES database notifications. ${ }^{14}$ Therefore, an incorrectly designed database can lead to inaccurate results, data redundancy, waste of time and perpetuation of errors in health care. ${ }^{15}$

\section{Conclusions}

the prototype of the database, as a result of this work, indicates a potential service level contribution to improve communication between members of local, national and international pharmacovigilance, producing resources, regulations and knowledge for the population and health professionals. In addition to these advances, the database will achieve scientific and technological resources that will avoid delays in entering and querying data, optimizing validation time, reporting, information generation, security and data confidentiality. For its execution it will be necessary to homologate the data, populate all the data in the $\mathrm{DB}$ and define the computational environment to be installed.

In addition, we wish to facilitate the information programs on drug harm and benefits, on the pharmaceutical industry itself and the means of dissemination. In the short term, it aims to promote effective communication and a better understanding of the community about the benefits and harms associated with medications, and to encourage the principles of a good communication practice and the harmonization of regulatory activities in pharmacovigilance.

\section{Funding Source}

The authors declare that the research did not receive funding for its realization

\section{Contributors}

LACBN and ICM contributed with the conception, design, analysis and interpretation of data; LACBN, ICM and SRY participated in the writing of the article and the relevant critical review of the intellectual content, final approval of the version to be published and the guarantee of the accuracy and integrity of any part of the work.

\section{Conflicts of Interest}

The authors declare no conflicts of interest.

\section{References}

1. Organização Mundial da Saúde. Departamento de Medicamentos Essenciais e Outros Medicamentos. A importância da farmacovigilância / Organização Mundial da Saúde, Brasília: Organização Pan-Americana da Saúde, 2005.

2. Brazil. Portaria n ${ }^{\circ} 1.660$, de 22 de julho de 2009. Diário Oficial da República Fderativa do Brasil, Poder Executivo, Brasília, DF, 27 jul. 2009b. Seção 1, p. 45.

3. Institute of Medicine. Crossing the Quality Chasm: A New Health System for the 21 st Century. Washington, DC: National Academy Press, 2001.

4. Trifiro G, Pariente A, Coloma PM et al. Data Mining on Electronic Health Record Databases for Signal Detection in Pharmacovigilance: Which Events to Monitor? Pharmacoepidemiology and Drug Safety, 2009, 18(12): 11761184.

5. Institute of Medicine. Health Databases and Health Database Organizations: Uses, Benefits, and Concerns. Washington, DC: National Academy Press, 1994.

6. Date, CJ. Introdução a Sistema de Banco de Dados, 7a edição. Rio de Janeiro: Campus, 2000.

7. Schneeweiss S, Avorn J.A Review of Uses of Health Care Utilization Databases for Epidemiologic Research on Therapeutics. Journal of Clinical Epidemiology, 2005, 58(1): 323-337. 
8. Sabbatini, R ME. Uma Proposta de Estruturação e Implementação. Revista Informédica, 1993, 1(5): 5-8.

9. Caon S, Feiden IR, Santos MA. Desvios de Qualidade de Medicamentos em Ambiente Hospitalar: Identificação e Avaliação das Ocorrências. Rev. Bras. Farm. Hosp. Serv. Saúde, 2012, 3(1): 23-26.

10. Rector A. Clinical Terminology: Why is It so Hard? Methods of Information in Medicine, 1999, 1(1): 1-10.

11. Chile. Ministry of Health. Instituto de Saúde Pública. Terminologías de Codificación y su Rol em la Farmacovigilancia. Boletim de Farmacovigilância, jun. 2017.

12. Hennessy S, Bilker WB, Weber A et al. Descriptive Analyses of the Integrity of a US Medicaid Claims Database. Phamacoepidemiology and Drug Safety, 2003, 12(1): 103-111.

13. Peabody JW, Luck J, Jain $S$ et al. Assessing the Accuracy of Administrative Data in Health Information Systems. Medical Care, 2004, 42(11): 10661072.

14. Organização Mundial da Saúde. Boas Práticas de Farmacovigilância para as Américas, Washington DC: Organização Pan-Americana da Saúde, 2005.

15. Campbell RJ. Database Design: What HIM Professionals Need to Know. Perspectives in Health Information Management, 2004, 1(1):6-21. 